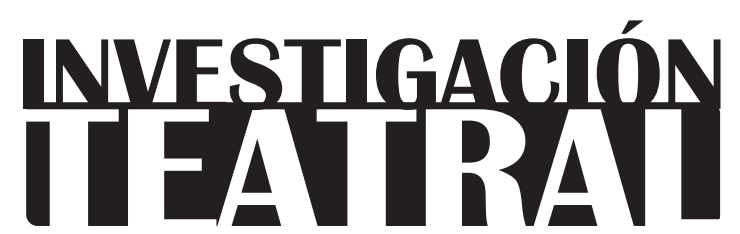

Revista de artes escénicas y performatividad

Vol. 12, Núm. 19

abril-septiembre 2021

Segunda época

ISSN impreso: $1665-8728$

ISSN electrónico: 2594-0953

Universidad Veracruzana

\title{
La violencia como medida disciplinaria extrema en Las dulces compañías, de Óscar Liera
}

Santos Javier Velázquez Hernández*

\footnotetext{
* Universidad Autónoma de Sinaloa, México. e-mail: javier_velazquezh@uas.edu.mx
}

Recibido: 25 de agosto de 2020

Aceptado: 10 de diciembre de 2020

Doi: $10.25009 /$ it.v12i19.2666 


\title{
La violencia como medida disciplinaria extrema en Las dulces compañías, de Óscar Liera
}

\section{Resumen}

Este artículo analiza dos obras del dramaturgo mexicano Óscar Liera, Bajo el silencio y Un misterioso pacto, desde la perspectiva de la historia cultural, a partir de la teoría en torno al poder de Michel Foucault. Se destaca la forma en que las disposiciones tradicionales emanadas del machismo, a través de un grado irracional del poder -la modalidad instrumental para preservar el orden moral establecido es sobre todo la violencia física, cuando la violencia simbólica ha dejado de funcionar-, ejercen un dominio absoluto sobre el otro, el anormal. Con estas obras, Liera buscó renovar tanto estética como ideológicamente esta temática en los años ochenta.

Palabras clave: dramaturgia; relaciones de poder; género; identidad; cultura; México.

\section{Violence as an Extreme Disciplinary Action in Las dulces compañías, by Oscar Liera}

\begin{abstract}
This article analyzes two works by Mexican playwright Oscar Liera: Bajo el silencio and Un misterioso pacto, from the perspective of cultural history, based on Michel Foucault's theory on the technologies of power. The way in which the traditional dispositions emanating from "machismo", through an irrational degree of power -the instrumental modality to preserve the established moral order is above all physical violence, when symbolic violence has ceased to function-, exercise absolute control over the other, the abnormal. With his plays, Liera sought to aesthetically and ideologically renew these topics within theatre of the eighties.
\end{abstract}

Keywords: dramaturgy; power relations; gender; identity; culture; Mexico. 


\title{
La violencia como medida disciplinaria extrema en Las dulces compañías, de Óscar Liera
}

\author{
A manera de tortura psicológica, \\ se busca regresar al individuo desviado a lo que se considera \\ "normal", moral.
}

M. Foucault

\section{Introducción}

$\mathrm{E}$ ste artículo tiene como propósito analizar dos obras del dramaturgo mexicano Óscar Liera (1946-1990), desde la perspectiva de la historia cultural, tomando como punto de partida la teoría de Michel Foucault en torno al poder. La decisión de abordar la dramaturgia lieriana obedece a su naturaleza realista, que provee más eficazmente una representación del mundo social al recrear sus conflictos y dilemas, y a su manifiesta intencionalidad política. La inscripción en la corriente del realismo por parte de Liera fue consciente, pues a Gilda Salazar le señaló que "el teatro debe reflejar la realidad que estamos viviendo. Evadir la realidad es lo que no podríamos hacer" ("El teatro, lenguaje de la vida diaria” 2), mientras que a Pedro Pablo Martínez le reveló su postura ideológica: el teatro es un juego político, "es un juego y un signo. Me interesa mucho el cómo jugamos y el cómo significamos" ("La vida es juego" 3), pero con Fernando de Ita fue más preciso al exponer sus temas e intereses: "Lo que más presente está en mi 
teatro como una obsesión es, quizá, el problema religioso [...] Me obsesiona como temática la familia y mucho más aún el manejo del poder, los juegos de poder" ("El teatro en México" 20). Estas autorreferencias son importantes para el propósito de este artículo, ya que marcan la pauta -el afán realista, la naturaleza política, la recreación del poder- para abordar la estrategia que el autor sinaloense empleó en su poética: los juegos de poder en el que se desplazan sus personajes.

En otro ámbito, Michel Foucault concibió al poder como un juego de fuerzas. ${ }^{1}$ Si bien su interés primordial se centró en estudiar cómo se constituye el sujeto (la subjetividad), ${ }^{2}$ una de sus conclusiones es que ésta se crea mediante las relaciones de poder y el discurso, las cuales elaboran las prácticas divisorias ${ }^{3}$ del mundo social que construyen las identidades, al proporcionar a las personas una idea de sí mismas y de reconocimiento ante los demás (Garvey y Stangroom 326-327). Para Foucault, las formas de dominación se diseminan en la sociedad: provienen de las instituciones, pero sobre todo de los individuos, ya que unos actúan sobre las acciones de otros (bajo el esquema influencia/resistencia); esto es, las relaciones sociales -que constituyen una red o malla ("Las mallas del poder" 242)- están atravesadas por el poder y sus mecanismos son inherentes a las relaciones de producción, las relaciones familiares y las relaciones sexuales (de manera circular, éstas son su efecto y su causa) ("Clase del 11 de enero" 16-17). ${ }^{4}$

Así, desde el siglo XVIII se ha venido perfeccionando la tecnología del poder anatomopolítico: el biopoder es la forma cada vez más fina y sutil en que se ha construido el ordenamiento y la regulación social; para Foucault, "la sumisión de los cuerpos mediante el control de las ideas, [...], como principio en una política de los cuerpos, [es] mucho más eficaz que la anatomía ritual de los suplicios. [... Este régimen] no fue únicamente una teoría del individuo y la sociedad; se desarrolló como una tecnología de los poderes

1 Como anécdota, Liera estudió Actuación en la Universidad de Vincennes, "la legendaria escuela fundada en 1968 por Merleau-Ponty y Louis Althusser, entre otras luminarias, y ahí tuvo noticias de la obra en construcción de Michel Foucault porque era uno de los maestros estrellas de aquel experimento formativo que fue uno de los centros de agitación en el mayo del 68 francés" (Ita párrafo 2).

2 La subjetividad se refiere a la forma en que nos vemos a nosotros mismos, cómo vemos a las otras personas y cómo somos vistos por ellas. Esto es lo que Roger Chartier, entre otros, denominan representación colectiva (35).

3 Estas divisiones del mundo social categorizan y clasifican de acuerdo con la distinción de normal y anormal, cuerdo y loco, lo permitido y lo prohibido, etcétera. Otras dos formas de objetivación del sujeto son la clasificación científica y la subjetivación (Garvey y Stangroom 326-327).

4 Tales relaciones pueden ser analizadas históricamente en un campo determinado en sus coordinaciones laterales, subordinaciones jerárquicas, isomorfismos, de una manera lógica, coherente y válida (16-17). 
sutiles, eficaces y económicos, en oposición a los gastos suntuarios del poder de los soberanos" (Vigilar y castigar 108).

En este sentido, considero que Bajo el silencio (1985) y Un misterioso pacto (1987), ${ }^{5}$ piezas que integran la tetralogía Las dulces compañías, son un excelente laboratorio para observar cómo se expresa el poder para disciplinar los cuerpos a través de disposiciones tradicionales, diversas medidas instrumentales y grados de racionalización con el objetivo de conservar el orden moral. Pero también para ver que cuando esas disposiciones tradicionales son insuficientes debido a una fuerte resistencia, se despliega entonces la violencia como una medida disciplinaria radical; donde hay poder, señala Foucault, hay resistencia, y ésta es tanto más real y eficaz en tanto se encuentra en el lugar exacto en que se ejercen dichas relaciones de poder (Un diálogo sobre el poder 82). Estas obras muestran que la "anatomía ritual de los suplicios" no había desaparecido y era dirigida contra, precisamente, quienes opusieran una mayor resistencia; en una lectura histórica, es un cuestionamiento a las agresiones físicas que padecían los "anormales", aquellos que son segregados por la sociedad por los prejuicios morales y el discurso jurídico o médico construido en torno a ellos. El adjetivo "dulces" anuncia, por contraste, una crítica a la nada sutil forma de la barbarie: la agresión física. En este sentido, las luchas sangrientas del pasado no fueron sustituidas por las luchas de representación en un país como México en los años ochenta, sino que aún se inscribían con rigor en los cuerpos físicos. ${ }^{7}$ Para Foucault el poder no es una propiedad, sino algo que está en juego y actúa tanto con mecanismos represivos e ideológicos (oculta, reprime, impide) como de forma positiva al producir lo real, y transforma a los individuos y produce la normalización a través de los discursos (Morey V-VI). Sin embargo, para Liera el poder presentaba una distorsión o regresión histórica: el sistema disciplinario, al no haber alcanzado un nivel de refinamiento, se volvía en un castigador de la alteridad y se erigía contra los cuerpos y las mentes que se "desviaban" de la normalidad al grado extremo de decretar su muerte.

$5 \quad$ En 1987, Liera publicó el libro Las dulces compañías, que agrupaba las dos obras mencionadas junto con "Al pie de la letra" (1982) y "Los negros pájaros del adiós" (1988); en 1988 Julio Castillo dirigió las obras gemelas "Bajo el silencio" y "Un misterioso pacto" bajo el título conjunto Dulces compañías.

6 Véase Michel Foucault, Los anormales (2007).

7 Cabe mencionar las agresiones violentas que sufrió la Infantería Teatral de la Universidad Veracruzana el 28 de junio de 1981 al escenificar la obra Cúcara y Mácara en el teatro Juan Ruiz de Alarcón, de la unam, en la Ciudad de México. Véase, entre otros, José Agustín, "Cúcara y Mácara. Pégale, que ella fue", Excélsior, México, 3 de julio de 1981, p. 7-A. 


\section{El anormal y la barbarie: las ataduras del siglo $\mathrm{xx}$}

La disciplina de los cuerpos y del deseo erótico no sólo se expresa a través de instrumentos del orden moral, como la sanción, la prohibición o la exclusión en las relaciones del núcleo familiar, sino que también alcanza el castigo físico a través de la violencia -cuando aquellas prácticas han dejado de funcionar- en el ámbito de las relaciones sociales. Esta situación es la que recrea Óscar Liera en dos obras de naturaleza urbana: Bajo el silencio y Un misterioso pacto, piezas breves en las que expresa cómo la lucha de fuerzas - una ideología dominante proveniente del machismo y otra que resiste, la del otro- se torna en una disputa sangrienta a través de las agresiones corporales que culminan incluso con la muerte. La denuncia de esta trilogía es esta: aun cuando en el siglo xx "los mecanismos de la represión habrían comenzado a aflojarse" (Historia de la sexualidad I 146), como advierte Foucault para el mundo occidental, en México las ataduras morales aún daban pie a la expresión de la barbarie. La no aceptación de la anomalía -en relación con la sexualidad-por parte de uno de los personajes, se traduce en un acto violento en contra del que sí ha reconocido y aceptado su condición. El victimario representa el sistema patriarcal, y en este marco, el autor realiza un ejercicio de resistencia, de crítica, al buscar crear conciencia y empatía con la víctima. Precisamente, es este uno de los temas relevantes del dramaturgo, ya que fue, como señala Olvera Mijares, parte "de su lucha política a favor de los desposeídos en general y los grupos minoritarios, como son las mujeres y los homosexuales" ("El accidentado viaje" párrafo 6).

Mientras que la sociedad ve al individuo con una preferencia sexual diferente como un anormal, el dramaturgo invierte los términos y expone al victimario, aquel que trata de "corregir" mediante la violencia física, como el verdadero monstruo. Si bien Liera buscó reflejar la realidad de su tiempo, a través del género de la farsa subrayó con trazos gruesos los vicios y el desorden moral; la farsa le dio la posibilidad de subvertir lo cotidiano, como le revelaba a Peralta: "Una subversión donde no existen límites, donde el juego es de carácter macabro, y que nos lleva a reflexionar, querámoslo o no, sobre los acontecimientos del mundo" ("La farsa es lo más subversivo" 16). A través de lo hiperbólico, tanto de lo grotesco como de lo ridículo, el dramaturgo Óscar Liera pretendió concientizar al público. De este modo, en los dos breves dramas aquí abordados, que juntos recibieron el título de Las dulces compañías para su representación, la violencia es muy extrema y constituye una crítica al sistema disciplinario y a las propias instituciones que lo conforman.

Esto es llevado a cabo con una gran economía de medios para su representación, pues sólo aparecen tres personajes en las dos piezas: el Tipo, que aparece en ambas; en una está con Nora y en la otra con Samuel. Igualmente, la trama se desarrolla en dos departamentos 
del mismo edificio, lo cual indica escenarios similares. En el de Nora, que es maestra de Geografía, hay "antiguos mapas colgados a la pared, estantes con libros, lámparas encendidas, pinturas modernas y copias perfectas de cuadros antiguos. Colores pasteles tibios y luminosos. Cortinas cálidas. Muebles, ceniceros, figuras de cerámica y de madera tallada"; mientras que "arquitectónicamente [el] de Samuel es idéntico al de Nora, sólo que el decorado es diferente. No hay mapas colgados en la pared, ni estantes con libros, lámparas encendidas, pinturas modernas, ni copias perfectas de cuadros antiguos. Los colores no son pastel, ni tibios, ni luminosos [...]" (Teatro completo I 585).

En 1988 Julio Castillo dirigió este montaje conjunto, en el que participaron Delia Casanova, quien encarnó tanto a Nora como a Samuel, y Eduardo Palomo, quien hizo el papel del Tipo; ambos realizaron un trabajo histriónico destacado que, en palabras de Alcaraz, llegó a ocupar "por derecho propio un primer plano patente" ("Las relaciones tan fructuosas" 8). En una de sus últimas entrevistas, Castillo mencionó que tomó esa decisión porque sentía el deseo de profundizar en el mundo de los asesinos, y con ello pasó del macrocosmos urbano al microcosmos doméstico, a la estancia de un pequeño departamento de uno de los miles de edificios de la Ciudad de México (Pingarrón 326-327). Asimismo, en 1989 Noberto Bogard, representante de Aura Productions, la llevó, en inglés, a The Raft Theatre de Nueva York, bajo la dirección de Alba Oms y con la participación de Mauricio Bustamante, Irma Bello y Roberto Medina (Reuben 7).

Una influencia directa de Las dulces compañías es La historia del zoológico (1958), de Edward Albee: el personaje de Jerry, igual que el Tipo hará con Nora y Samuel, establece una lenta y creciente relación de dominación psicológica en contra de Peter; Jerry es también de clase baja, de los suburbios, agresivo y manipulador, aunque al final él es la víctima. El contexto de la historia del escritor norteamericano también es diferente y simboliza el aislamiento entre el yo y la sociedad, ya que recrea la incapacidad de comunicación debido al individualismo. El personaje de Liera también es complejo y hace referencia a los seres anónimos que sobreviven en la gran urbe, esa donde "Cada uno de los barrios [...] tiene sus expresiones propias. La Ciudad de México es un texto que está por descifrarse, situémosla como texto para descubrir sus encantos o su horror y su espanto" ("Urbi et orbi" 8). Esa es otra apropiación de Liera: su experiencia de haber vivido en la capital del país, y de ahí que su crítica social tenga varias capas de significación.

De acuerdo con Bogard, estos dramas ofrecieron a los espectadores neoyorquinos una reflexión aguda sobre la violencia y la soledad; el drama "causó impacto por la perfección de sus postulados, de su crítica y tan obsesiva como aguda observación de la existencia contemporánea en la urbanidad deshumanizada", e incluso alguien la definió casi como "dinamita... una experiencia explosiva... definitivo reflejo de la realidad social" (Bogard 6). Liera logró captar los caracteres de la ciudad, pero también fue capaz de realizar una 
lectura del orden moral de su época. Similar recepción había tenido por parte de la crítica en México; fue vista como una crítica social, pero también psicológica y política; para Bert, por ejemplo, era un juicio a la clase media, recurrente en el uso de "elementos de marginación comprados y usados como un sucedáneo de la compañía y la sexualidad", lo cual hace "estallar ese pequeño mundo egoísta y amurallado, simbolizado en el departamento propio y la suma de sus objetos que serán destruidos junto con sus integrantes" (7).

Desde mi punto de vista, por un lado, en Las dulces compañías se retrata el fracaso de las instituciones disciplinarias: la familia, la religión y la cárcel. El Tipo es, en este sentido, un anormal, un ser excluido de la sociedad de la cual cobra venganza. En primer lugar, carece de identidad: no tiene nombre debido a que fue abandonado, según él mismo le revela a Nora: "A ver, yo, yo me crié en un orfanatorio, ni sé si tengo padres o hermanos, sepa la bola, me pasé toda la pinche infancia entre curas que eran los dueños del orfanatorio", y añade: "no sé ni qué día nací, ni si me llamo Arturo, o Carlos, o José" (Teatro completo I 595). A Samuel también le confiesa que "sería bien chingón tener un hermano; un hermano que es marino y que tiene aventuras, que llega de sus viajes y que cuenta a todos lo que ha vivido mientras la familia entera toma el café y no se oye ni el sorber de las tazas" (610).

El Tipo idealiza la vida familiar porque es una víctima del primer núcleo social y enganche de los demás sistemas disciplinarios y, en ese sentido, padece la expulsión: un cura le revela que fue regalado por su madre prostituta. Este es el segundo fracaso disciplinario: los religiosos fallan en su formación; cuando Nora trata de "rescatarlo" de las drogas y le sugiere un centro de integración -otra institución disciplinaria-, él se rebela y señala que se pasó la vida oyendo consejos de los curas y no sirvió de nada; pero además, dado que con sus compañeros del orfanatorio escapó a un prostíbulo para iniciarse sexualmente -otra alusión a la cultura del machismo-, un cura lo reprendió y lo dañó aún más al decirle: "No pueden meterse con esas mujeres porque alguna de ellas puede ser su madre.' (Pausa.) ¿Sabes lo que es eso? Aquí por dentro (del pecho) te cambian los cables de otra forma y ya no puedes pensar igual", y ello le ocasionó impotencia sexual: "Jamás pensé meterme en la cama contigo, no me interesa, no puedo; no puedo con las mujeres" (595). Por si ese trauma no fuera suficiente, después atraviesa por el sistema carcelario que, en lugar de lograr la reinserción social, lo corrompe más: "yo he estado en la cárcel, buey, y he estado un chingo de veces y te digo una cosa: es como vivir entre la mierda" (609); de hecho, la policía -la vigilante del orden y la seguridad, y encargada del sistema punitivo- es representada como distribuidora de drogas dentro del penal y violadora de los derechos humanos a través de la tortura.

De este modo, el Tipo se ha convertido en un ser marginal que usa el puro instinto para sobrevivir; en las acotaciones es descrito como alguien dotado de animalidad y cuyo 
único interés, lo que le ocasiona placer y evasión de la realidad, es la mariguana a la que es adicto y por la que es capaz de cometer cualquier crimen. En suma, Óscar Liera exhibe a través de este personaje cínico, inmoral y asesino una de las grandes fallas de la sociedad disciplinaria.

Sin embargo, por otro lado, y pese a que es un ser excluido, el Tipo es el agente encargado de vigilar el cumplimiento del "orden moral" del modelo barbárico que aún impera (como elemento fársico, el personaje está animalizado: es un bruto), de ahí que su método resulte irracional aun cuando diga cínicamente que no le gusta la violencia, "pero si no es por la buena, es por la mala. No hay de otra" (608). Como señala Olvera Mijares, "Liera se sirvió del socorrido cliché, pero también desenmascara: ahí donde parece haber un despliegue excesivo de virilidad, termina la jactancia y comienza el instinto" ("El accidentado viaje" párrafo 7). De nuevo, Óscar Liera construye un personaje que encarna el machismo que reprime y sanciona, incluso con la muerte, a quien elige desde la libertad y la independencia, hacer uso de su cuerpo como pagar por tener sexo, por ejemplo. Casi todo el tiempo el Tipo mantiene el control y el dominio sobre su víctima a través de los instrumentos de la coerción física y las órdenes agresivas: "(Se detiene con brusquedad y la mira con rabia.) ¡No trates de presumirme que sabes mucho, siempre habrá algo de lo que yo sepa más que tú!" (Teatro completo I 587), le dice a Nora (pero también a Samuel: "a lo mejor tú tienes estudio y sabes muchas cosas, pero siempre habrá una en la que yo sepa más que tú y allí te jodes") (611). Este saber más refuerza su poder y superioridad; por supuesto, lo que ellos ignoran es el destino fatal al que han sido condenados de antemano. El Tipo se autoerige como un ser superior que amonesta y aconseja; tanto a Nora como a Samuel les advierte de los peligros que entraña invitar a un desconocido a la casa: a Samuel cuatro veces le sugiere no meter desconocidos, y a Nora, una vez. Finalmente, a ambos el Tipo les subraya que le disgusta el desorden: con Nora, cuando él se dispone a lavar una taza, ella le dice que la deje, a lo que replica: "A mí me gusta el orden [...] Comienza uno por cosas pequeñas [...] Y cuando menos se da cuenta uno ya está hasta arriba" (600), mientras que a Samuel también lo reprende: "El desorden es muy malo, buey, muy malo. A mí, buey, a mí me gusta el orden, comienza uno por cosas pequeñas y cuando menos se da cuenta uno ya está hasta arriba" (616). No obstante, el orden que él concibe está distorsionado: se halla puesto de revés, y por eso, cuando Samuel le señala que es él quien vive en el desorden, el Tipo se pone frenético.

El Tipo, que usa el pretexto de la prostitución tanto con mujeres como con hombres para cometer robos y asesinatos, representa la doble moral de la sociedad que, monstruosa, castiga a otro paradigma del anormal: al que no encaja en la convención ni en el patrón de valores. Para dar cuenta de esta situación anómala, y valiéndose del maniqueísmo, Liera representa al diferente como alguien decente, exitoso y honesto, perte- 
neciente además a un estatus social basado en los méritos: Nora es profesora y Samuel realiza teatro guiñol. Esta puesta de revés es para mostrar las costuras, los mecanismos con los que opera el poder disciplinario que implementa la familia y otras instituciones a través de la hipocresía, los prejuicios y la deshumanización. Es significativo, por tanto, analizar la representación del "desorden" en que viven Nora y Samuel, ya que lo "mal visto" se convierte en una extensión de la mirada de la misma sociedad, de sus juicios y sus valores.

El personaje de Nora tiene una clara filiación literaria, pues remite al personaje de Casa de muñecas de Henrik Ibsen, y al mismo tiempo se enmarca en los resultados de la lucha feminista de los años sesenta. La similitud con el personaje de Ibsen radica en que, contrario a los valores de la época, Nora se libera del yugo matrimonial y exime a su marido de cualquier obligación para con ella: "En cualquier caso, yo te dispenso de obligaciones. No conviene que te sientas ligado, puesto que me desligo yo. Libertad plena de una parte y de otra. Toma, aquí tienes tu anillo; devuélveme el mío" (95). Es decir, se trata de la representación de una mujer independiente y libre. Además, como el dramaturgo noruego, Liera también se propondrá retratar la descomposición moral de la sociedad, el mundo de las apariencias y el influjo del capitalismo en las transformaciones, pero sobre todo habrá de dominar "la perspectiva individual, el deber de la persona para consigo misma" (Piña 85). La Nora de Liera es también una mujer liberada: ella estuvo en unión libre, pero fue un fracaso, y de manera similar al personaje ibseniano, dice: "no creo en el matrimonio, no me importan los niños, creo que los hijos son un estorbo, es todo" (Teatro completo I 599).

Esta semejanza literaria se debe a la influencia de Emilio Carballido, su maestro, quien escribió Nora en 1980 como homenaje a Ibsen, obra que versa sobre un personaje de la Ciudad de México que se libera de la rutina doméstica y del yugo matrimonial que la mantenían reprimida, "como si la vida se hubiera quedado sin jugo y sin colores" (Carballido 32). Liera también reformula ese personaje emblemático, con una mirada de cronista, pero además hace un guiño a una joven que conoció, según lo escribió en su diario el 30 de abril de 1970: "Nora me gusta, pero la siento tan lejos. Me prometió que estaríamos juntos" (Torres Sánchez 136). No obstante, es sobre todo una evolución del personaje ibseniano. Al invitar a un supuesto sexoservidor a su departamento, Nora ejerce su libertad de decidir sobre su propio cuerpo; como mujer independiente, trabaja como maestra de Geografía en el colegio San Esteban y vive sola. Ante el asalto del Tipo, ella señala: "yo he logrado tener esto poco que ves a base de grandes esfuerzos, nadie me ha dado nada, nadie da nada. Me he fregado estudiando y trabajando para poder lograr lo que tengo; para pagar la renta de este departamento tengo que dar muchas clases, revisar trabajos... nada es fácil" (Teatro completo I 596). Sin embargo, pese a la fortaleza de Nora, 
desde un inicio es sometida por el Tipo, quien la amonesta, sanciona y doblega a través de la coerción física o del miedo:

NORA: ¿Quieres un trago?

EL Tipo: Prefiero un café. No bebo. Te dije, ¿no?

NORA: No.

EL TIPO: Te dije. El alcohol me hace daño; me pone agresivo y me dan ganas de agarrarme a los golpes con cualquiera. Te dije.

NORA: Disculpa, no recuerdo. Te preparo el café. Siéntate. Ponte cómodo. Si quieres quítate los zapatos... lo que quieras... (585-586).

Mientras ella es servicial, él se muestra descortés: tres veces le señala "te dije" para advertirle su supuesta falta de atención. Y aunque pareciera existir un equilibrio de fuerzas, pues Nora emite algunas órdenes: "siéntate", "ponte", "quítate", éstas sólo son sugerencias para que el Tipo tenga una estancia placentera. De igual modo, la subordinación de ella se hace más patente cuando usa la fórmula de cortesía de disculparse - para introducir luego una erótica insinuación: "Si quieres quítate los zapatos... lo que quieras..."- ante una molestia de él que en realidad es una amenaza: el Tipo crea una imagen violenta de sí mismo, la cual irá reforzando más tarde, cuando le revele que trabajó en un barco y asesinó a Bocabrava, alguien que se la pasaba dándole órdenes. El apellido de ese personaje constituye otra amenaza también, pues indica la identidad de alguien que habría sido muy hablador y el destino que tuvo.

Asimismo, el Tipo casi todo el tiempo mantiene el control sobre Nora; cuando ella lo invita con coquetería a pasar a la recámara, él la frena y le llama incluso la atención: "No, hay que platicar. Primero hay que conocerse. Yo no puedo así como los animales, llegar a eso y adiós y uno ni se da el nombre" (586). Con esa expresión, rebaja a Nora a puro deseo sexual, la animaliza, en tanto que él se muestra como alguien superior, con dominio de sí. De a poco, el Tipo irá minando y socavando su dignidad: "NORA: Acepto también que he vivido en el desorden, acepto que esto es un robo, acepto todo lo que dispongas pero me urge el descanso: déjame ya, te lo suplico". Al final, el Tipo la castiga con la muerte -al proyectar en ella a la figura materna y el abandono-: “Perra, buscona, no te gustan los niños, te estorban los hijos y si tienes uno serías capaz de regalarlo como lo han hecho otras putas! Ahora sí ponte a descansar" (601). De este modo, Nora es disciplinada brutalmente por el representante de un sistema anómalo: por alguien que es también víctima al ser producto de una exclusión y una serie de fallas en las instituciones disciplinarias. Ella es, pues, castigada por ejercer su independencia y libertad, pero sobre todo por ser una mujer dueña de su cuerpo que hace uso del derecho para 
no formar parte del régimen reproductivo. Es significativo, por otra parte, que el Tipo padezca impotencia sexual: la carencia de su virilidad la suple con la sumisión violenta del cuerpo del otro.

La pieza Un misterioso pacto es una secuela, una prolongación de Bajo el silencio: ahora uno de los protagonistas es Samuel, junto con el Tipo. Más que poderse señalar una filiación literaria en esta obra, se trata de una autoapropiación de una parte de la vida del dramaturgo. Samuel es su alter ego; algunas alusiones son las siguientes: el personaje refiere que en su infancia conoció el teatro guiñol, el que "un día hicieron mis primas y mis tías como un acto sagrado para alejar la muerte del lecho de mi hermana. Es el guiñol que Pedro Carreón, un viejo maravilloso y casi santo, cargaba por las calles y las plazas" (615). La mención de los muñecos, de la familia y de la hermana enferma, así como de Pedro Carreón, son claros referentes extraliterarios: a los primeros, de niño, les decía pipirituches, y acerca de su hermana Carmen María, ella falleció en 1958, cuando él tenía 12 años (Torres Sánchez 49). Carreón Zazueta fue una figura señera del teatro guiñol en el país, al grado de ser conocido como el Señor Guiñol. Asimismo, cuando Samuel inventa que tiene un hermano que es marino, es algo a lo que Liera también recurría, como lo confiesa en su diario el 15 de marzo de $1971 .^{8}$ Otra referencia a su vida privada, finalmente, se encontraría en las líneas en que Samuel menciona que una vez tuvo una novia:

EL TIPO: (Suelta la carcajada.) ¡Una novia! (A los seres imaginarios.) Conocí a un puto que tuvo una novia. (Continúa riéndose).

SAMUEL: (Muy serio). Entonces yo no era puto. (El tipo, que también apesta a cebolla, deja de reírse. Samuel se vuelve muy reflexivo). O, más bien, en ese tiempo, quizá es que no sabía que lo era. Se llamaba Emilia. Emilia Jameston, Jameston..." (Teatro completo I 612).

En efecto, Liera tendría una novia en la Ciudad de México y de ella se conservan algunas fotografías, y "cuando estuvo en Europa se relacionó sentimentalmente con su maestra

8 "Yo quería un hermano. Nunca hubo tal. Oí a Beethoven. Una noche le escribí un poema, le decía cosas, pero no lo vio, no se lo enseñé, quizá otro día" (157). De hecho, según relata Torres Sánchez, un día de 1972, en el ensayo de Los cánticos de la muerte que se hacía en el teatro del IMSs, conoció al actor Sergio Lasso, quien debido a que tenía seis hermanos, le habría de decir: "si quieres te doy uno, a ver si las cosas resultan como te las imaginas'. Y Óscar aceptó la oferta, condicionándola a que ese hermano fuera, nada más y nada menos, el propio Sergio. Y como en eso quedaron, en adelante, y por muchos años, el apellido de Sergio, en lugar de Lasso, fue Liera. 'Este es mi hermano, Sergio Liera, solía presentarlo Óscar a sus amigos" (157). 
de francés, Martine. Vivió en su departamento, intimó con su familia, viajó con ella por el viejo continente y la llevó en alguna ocasión a Culiacán, hospedándola en casa de su hermana, pese al desconcierto de doña Adelina" (Torres Sánchez 106). Por otra parte, igual que Nora, Samuel representa la libertad individual: es alguien consagrado al trabajo del teatro, vive solo en un departamento - pertenece a la clase media- y dispone de su cuerpo y del placer con total independencia. Dada su condición física y su experiencia de hombre maduro -tiene 46 años-, ofrece una mayor resistencia al chantaje y al manipuleo del Tipo, y alcanza a dar órdenes, aunque es fácil de seducir. Desde un principio Samuel trata de establecer con claridad los límites, pues cuando el Tipo le dice que se va, él le contesta: "(Muy tranquilo.) Como quieras; ya sabes dónde está la salida; la puerta es muy amplia y no tiene llave" (Teatro completo I 603). A su vez, cuando aquél le pregunta para qué lo invitó, él le responde sin rodeos que bien sabe para qué, lo cual lo desconcierta: "Eres muy directo y muy cabrón. Cuando veníamos eras muy amable. El café me gusta helado. Cuando veníamos eras más amable" (604). Sin embargo, poco después es sometido a la fuerza y con violencia y esa relación, por un momento simétrica, se torna tensa y desequilibrada, sobre todo cuando el Tipo lo agrede para doblegarlo ante la negativa de darle su dinero; tras darle un manotazo en la cara, lo insulta: "iNo te burles, pendejo!, imariqueta de mierda, estoy hablando en serio, viene la feria o quieres que te deshaga toda la pinche cara! (Samuel se ha resuelto a llorar.) Viene la billetiza por la buena o por la mala. ¿Qué onda?, ¿quieres que te rompa el espinazo a patadas?" (607).

El método de la violencia física es acompañado con el de la violencia verbal. Poco a poco, el Tipo apela a su condición de macho, a su supuesta superioridad moral, aquella que le recalca su preferencia sexual ("mariqueta de mierda"), para subordinar a Samuel. El rol del macho se hace patente también cuando menciona: "A mí, este rollo con otro buey, no me pasa, maestro, ni con las viejas; yo cero con el sexo, cero, cancelado" (612). Pero, como es notorio, se trata de un individuo traumado: el sexo es para él una aberración, un valor que reduce al hombre al estado primitivo, ya que también a él le dice desde un principio y como una condición: "No, hay que platicar, hay que conocerse, yo no puedo así nomás como los animales..." (602). La cancelación del sexo debido a un trauma lo conduce a castigar, a disciplinar, a los que buscan establecer una relación sin ataduras.

Pero, además, el Tipo, al emanar de una sociedad disciplinaria fallida, usa sus propios dispositivos, que están distorsionados, para inculcar reglas y normas de vida de una sociedad que él reconoce homofóbica; por ejemplo, cuatro veces le advierte, con tono paternalista, de lo peligroso que es meter a la casa a desconocidos: "[...] no lo andes haciendo m'hijo porque hay mucho malviviente cabrón" (606), y "más para los putos, porque a esos nadie los quiere" (609). A través del método del miedo, busca que Samuel 
comprenda el "desorden" en que vive. Por eso, también recurre a la amenaza de armar un escándalo para que los vecinos sepan que es homosexual; no obstante, Samuel está seguro de su preferencia sexual: "No. No tengo miedo; mis vecinos saben lo que soy y no me da cuidado. Yo no manejo dos vidas, vivo como pienso y no me escondo de nadie, ni de nada [...]" (616). La resistencia de Samuel, en este sentido, es saberse superior al Tipo, pues habita el mundo sensible del arte, y al enfrentarlo logra incluso tener el dominio: "Siento pena por ti; he sobrepasado la barrera del espanto; no me inspiras miedo, me das lástima y me das asco" (615). De tal modo lo controla, que el Tipo transita por el miedo, la angustia, la rabia y la desesperación. En el clímax, Samuel ha logrado subordinar al Tipo y es capaz de mandarlo o replicarle: "Si quieres agua, traila [sic] tú, ya sabes dónde está la cocina" (617).

Sin embargo, el Tipo se vale de un instrumento más sutil, al ver que las amenazas o la coerción física no han dado resultados, recurre a la seducción: "Tienes unos ojos de pícaro, (muy próximo a él.) ¿Ya te habían dicho que tienes unos ojos de pícaro? (Le acaricia con la boca la mejilla y se lanza en busca de sus labios.) Y es curioso, porque también podría decirse que en tu mirada se resume toda la tristeza de las cárceles" (617). Y en seguida, el error de Samuel sería confiar en alguien, creer en el amor, ejercer su libertad. De este modo, Óscar Liera, a través de la empatía con la víctima y de la crítica creada en el discurso dramatúrgico, implementa una resistencia al poder coercitivo de la institución familiar. La familia conservadora, mediante este tipo de discursos surgidos del arte, era desestabilizada, y el teatro de Liera mostraba esa situación.

\section{Conclusiones}

En estas dos obras de naturaleza urbana, Bajo el silencio y Un misterioso pacto, Óscar Liera muestra a la violencia tanto simbólica como física como una modalidad instrumental cuyo objetivo es conservar el orden moral; se trata de un recurso primitivo e instintivo con el que actúa el patriarcado y, en su prolongación, el machismo. Ambas obras exhiben un claro sistema de diferenciaciones basado en la cultura y el estatus mediante el binomio normal/anormal; sin embargo, dicho sistema está invertido, acaso como una forma de señalar tanto lo opresivo como lo absurdo de las normas, los códigos y las prácticas sociales aceptados. Los grados de racionalización en las relaciones de poder que se observan en estas obras son, asimismo, primitivos: la violencia física, principalmente, muestra su eficacia para la obtención de los objetivos; en este sentido, al estar abordado el mundo social desde la farsa, se trata más bien de un grado de irracionalidad, el cual apoya una forma de institucionalización respaldada en la costumbre o la tradición. 
Con Bajo el silencio y Un misterioso pacto, Liera realiza una crítica social, pues es desde la perspectiva del Tipo que se juzga, violenta y castiga con la muerte el comportamiento y la sexualidad de Nora y Samuel, aun cuando ellos son independientes, honestos y libres de decidir sobre su cuerpo; asimismo, la profesión de ambos carece de importancia, si bien la resistencia que ejercen termina por costarles la vida: Nora, maestra de Geografía, es sometida a un juego y pierde su sentido de orientación, mientras que Samuel, de oficio titiritero, es manipulado como si fuera él mismo uno de sus juguetes. La resistencia que ponen pasa por la cuestión física, pero sobre todo por la simbólica: son sus valores morales, la honestidad y la razón lo que incita las agresiones sin medida. Y es la fuerza física del Tipo la que hace que tenga un papel dominante, aunque él se autorrepresente como alguien "normal" y amante del "orden" a pesar de su trauma (fue abandonado por su madre, una prostituta), su adicción (es marihuano) y su vandalismo (es ladrón y asesino). El sistema de diferenciación, desde la perspectiva del dramaturgo, está trastocado: lo que debería ser considerado como normal, es "anormal" (las vidas de Nora y Samuel), mientras que lo anormal se encuentra normalizado (la actitud y las consecuencias realizadas por el Tipo), lo que provoca una relación desigual de fuerzas con soporte en un ejercicio irracional del poder emanado del machismo. Es así que los raros, los anormales, los otros, son sometidos a prohibiciones, coerciones y exclusiones, pero también a la violencia extrema para "disciplinar" sus cuerpos y mentes (las conductas, los gestos, los deseos) y con ello restablecer la "normalidad", esto es, lo aceptado y establecido por las normas, códigos y prácticas sociales.

En suma, con estas obras Liera criticaba la institucionalización de las relaciones sociales basadas en las disposiciones tradicionales, y hacía notar, con ello, la urgencia de establecer un nuevo orden social. Liera conocía, desde luego, la tradición literaria mexicana en torno a los personajes anormales como el gay o la lesbiana, ${ }^{9}$ y por eso, a través de obras como las analizadas - pero también como Los camaleones (1979) o La infamia (1990)-, se propuso realizar una renovación tanto ideológica como estética.

9 Por ejemplo, Cada quien su vida, de Luis Basurto, le parecía "una obra asquerosamente moralista”, y decía que si se abordaba "la loca" en el teatro de carpa, en el chiste, en el cabaret, sólo era "desde un punto de vista peyorativo, para hacer el chiste, ponerlo en ridículo. Vivimos en una sociedad machista y al macho le da mucha tranquilidad ver que hay hombres femeninos" (Liera 55-57). 


\section{Fuentes consultadas}

Alcaraz, José Antonio. "Las relaciones tan fructuosas / I". Unomásuno, 11 de julio de 1988, p. 8. Bert, Bruno. "El terror como juego de excitación. Dulces compañías". Tiempo Libre, 14 de julio de 1988, p. 7.

Bogard, Norberto. "Para hacer teatro en Nueva York debes ser desafiante: Norberto Bogard”. Entrevista de Gonzalo Valdés Medellín. Escriba, núm. 22, 18 de febrero de 1990, p. 6.

Carballido, Emilio. D. F. 52 obras en un acto. México: FCE. 2006, p. 32.

Chartier, Roger. "La nueva historia cultural". El presente del pasado. Escritura de la historia, historia de lo escrito. México: UiA. 2005, p. 35.

Foucault, Michel. "Las mallas del poder", Estética, ética y hermenéutica. Obras esenciales, vol. III. Barcelona: Paidós, 1999, p. 242.

Foucault, Michel. Historia de la sexualidad 1. La voluntad de saber. México: Siglo xxi, 1998, p. 146.

Foucault, Michel. Los anormales. Buenos Aires: FCE. 2007.

Foucault, Michel. “Clase del 11 de enero de 1978”. Seguridad, territorio, población. Buenos Aires: FCE, 2006, pp. 16-17.

Foucault, Michel. Vigilar y castigar. Nacimiento de la prisión. Buenos Aires: Siglo xxI, 2002, p. 108.

Garvey, James y Jeremy Stangroom. "Poder, conocimiento y subjetividad". La historia de la filosofía. Una historia del pensamiento occidental. México: Taurus, 2012, pp. 326327.

Ibsen, Henrik. Casa de muñecas. México: Millenium, 1999, p. 95.

Ita, Fernando de. "El teatro en México está vivo; en algunos años habrá un auge importante, señala el dramaturgo Óscar Liera”. Unomásuno. 26 de enero de 1984, p. 20.

Ita, Fernando de. "Óscar Liera: regalo navideño". 24 de diciembre de 2014. Teatro Mexicano, http://teatromexicano.com.mx/2449/oscar-liera-regalo-navideno/ (párr. 2)

Liera, Óscar. "El teatro y lo gay". Del otro lado, núm. 1, 1992, pp. 55-57.

Liera, Óscar. "Urbi et orbi". Diorama de la Cultura, Excélsior. 14 de octubre de 1979, p. 8.

Liera, Óscar. Teatro completo I. Culiacán: SEPYC / COBAES / DIFOCUR, 1997.

Martínez, Pedro Pablo. "Óscar Liera: la vida es juego (pero político).... La guía, núm. 103, Novedades. 15 de septiembre de 1983, p. 3.

Morey, Miguel. "Introducción". Un diálogo sobre el poder y otras conversaciones. Madrid: Alianza Editorial, 2000, pp. v-vi, 82.

Olvera Mijares, Raúl. "El accidentado viaje de Óscar Liera”. La jornada semanal, núm. 833, 20 de febrero de 2011, párr. 7. https://www.jornada.com.mx/2011/02/20/sem-raul.html 
INVESTIGACIÓNTEATRAL

Revista de artes escénicas y performatividad

Vol. 12, Núm. 19

abril-septiembre 2021
La violencia como medida disciplinaria extrema

en Las dulces compañías, de Óscar Liera

Santos Javier Velázquez Hernández

Peralta, Braulio. "La farsa es lo más subversivo del teatro contemporáneo: Óscar Liera". Unomásuno, 10 de febrero de 1983, p. 16.

Pingarrón, Gabriel. Todo es teatro. La vida en el arte de Julio Castillo. México: Nostromo Editores / Navarro Ediciones, 2011, pp. 326-327.

Piña, Juan Andrés. "Henrik Ibsen: retratista sicológico y fotógrafo social”. En Henrik Ibsen, Casa de muñecas. Santiago: Pehuén Editores, 2001, p. 85.

Reuben, María Elena. "La obra Sweet Companions. Electrizante estreno del Teatro RAFT". Escriba, núm. 22, 18 de febrero de 1990, p. 7.

Salazar Antunes, Gilda. "El teatro, lenguaje de la vida diaria. Una entrevista con Óscar Liera". El Suplemento de El Debate, 15 de noviembre de 1987, p. 2.

Torres Sánchez, Rafael. Óscar Liera. El niño perdido. México: Juan Pablo Editores, 2000, pp. 49, 106, 114, 136, 157. 